\title{
MANUFACTURING \& PERFORMANCE ANALYSIS OF THERMOSYPHON HEAT PIPE CHARGED WITH Z NO FOR HEAT TRANSFER ENHANCEMENT
}

O. M. Kshirsagar, Suchit Kawade, Vishal Ghodase, Mandar Kirange, and Shrikant Kamble.

\begin{abstract}
This study presents the experimental performance of a thermosyphon heat pipe charged with the ethanol-methanol mixture. The objective of this work is to study the combined effect of coolant flow, tilt angle and thermal load on the thermal performance of the thermosyphon. Thermosyphon was manufactured using a $1000 \mathrm{~mm}$ long copper tube with inner and outer diameters of $24 \mathrm{~mm}$ and $26 \mathrm{~mm}$ respectively. The working fluid used in the thermosyphon is a binary mixture of ethanol and methanol. Experiments were carried out on the inclination angle $40 \mathrm{o}$ to $90 \mathrm{o}$, the flow rate of the coolant $3.6 \mathrm{~kg} /$ $h$ to $21.6 \mathrm{~kg} / \mathrm{h}$, the thermal load from $25 \mathrm{~W}$ to $200 \mathrm{~W}$. The distribution diagrams thermal and thermosyphon heat transfer efficiency and measured. The results showed that the maximum heat transfer efficiency is $86.39 \%$, which is greater than $3.6 \mathrm{~kg} / \mathrm{h}$ of coolant with a tilt angle of $80 \mathrm{o}$ and a heat load of $190 \mathrm{~W}$ The binary mixture has a better thermal conductivity of the pipe thermosyphon.
\end{abstract}

Index Terms —Thermosyphon Heat Pipe; Ethanol; Methanol, Nanofluids;

Reference to this paper should be made as follows:

O. M. Kshirsagar, Suchit Kawade, Vishal Ghodase, Mandar Kirange, and Shrikant Kamble (2020), "MANUFACTURING \& PERFORMANCE ANALYSIS OF THERMOSYPHON HEAT PIPE CHARGED WITH Z NO FOR HEAT TRANSFER ENHANCEMENT" Int. J. of Mechanical, Robotics and Production Engineering, Vol. 7, No. 1, pp. 10-16.

Biographical notes:

O. M. Kshirsagar, Asst. Professor in Department of Mechanical Engineering, JSPM Narhe Technical Campus, Pune, India..

Suchit Kawade, Vishal Ghodase, Mandar Kirange, and Shrikant Kamble are scholars in Department of Mechanical Engineering, JSPM Narhe Technical Campus, Pune, India.

Published by: International Associations of Professionals and Technical Teachers (IAPATT) 


\section{INTRODUCTION}

The waste heat is heat generated in the process by fuel combustion or chemical reaction and released into the environment, although it can be reused for useful and economic purposes [1,2,3]. The essence of heat is not quantity but rather its value. This heat recovery strategy is partly dependent on the temperature and economic aspects of the waste gases. Direct and indirect benefits are involved in heat recovery $[4,5]$. Remaining heat recovery has a direct impact on the efficiency of processes and the indirect benefits include pollution reduction, equipment size and excess air consumption.

\section{HEAT PIPE HEAT EXCHANGERS}

Heat exchanger heat exchangers have regular winding channels, but each consecutive pipe is independent and is not connected to other pipes. Each tube is made with internal capillary material. The tube is drained, filled with a compatible liquid according to the temperature range and closed separately. When the pipes are horizontal, half of the heat exchanger acts as an evaporator and the other side acts as a condenser [6]. The high-temperature airflow runs from the vapor generator side and the low-temperature air flow passing through the condenser side. High temperature air flow passes half of all pipes. When the operating fluid is reheated and vaporized in half of the evaporator, the internal vapor pressure gradient drives the gas into the condenser. At the end of the condenser, the liquid releases hidden vapor energy when sealing, whereby the air flow is heated at a low temperature. The liquid returns to the vaporizer end through the inner recess $[7,8]$.

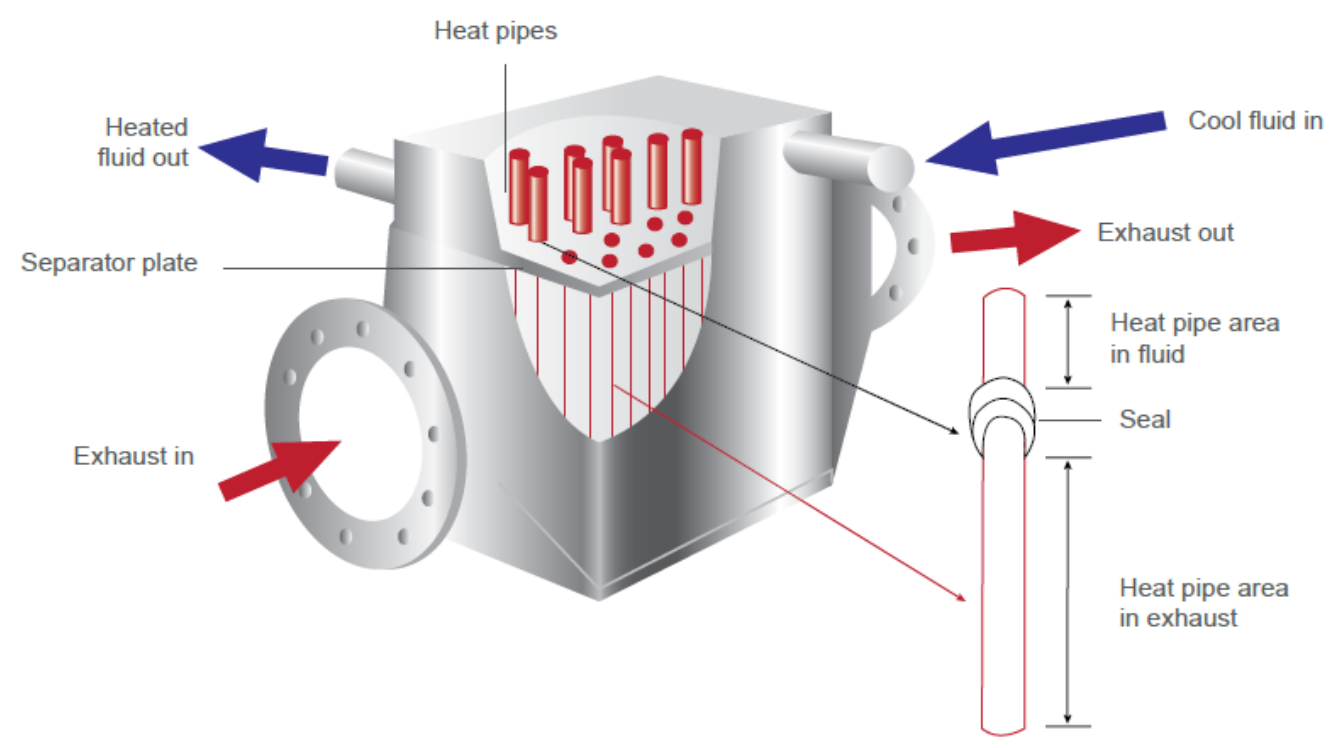

Figure1: Heat pipe heat exchanger 


\section{HEAT TRANSPORT IN NANOFLUIDS}

A. Models for Thermal Conductivity of Nanofluids

Following models have been proposed by various researchers, which give the explanation for enhancement in thermal conductivity of nanofluid [9].

Brownian motion of the particles

$>$ Interfacial layering of liquid molecules.

B. Thermo Physical Properties of Nanofluid

\begin{tabular}{|l|l|l|l|l|l|l|}
\hline Property & Water & $\begin{array}{l}\text { Ethylene } \\
\text { Glycol }\end{array}$ & $\mathrm{Cu}$ & $\mathrm{Al} 2 \mathrm{O} 3$ & $\mathrm{CuO}$ & $\mathrm{TiO} 2$ \\
\hline $\mathrm{C}(\mathrm{J} / \mathrm{kg} \mathrm{K})$ & 4179 & 2415 & 385 & 765 & 535.6 & 686.2 \\
\hline$\rho(\mathrm{kg} / \mathrm{m} 3)$ & 997.1 & 1111 & 8933 & 3970 & 6500 & 4250 \\
\hline$\lambda \mathrm{L}(\mathrm{W} / \mathrm{m} \mathrm{K})$ & 0.605 & 0.252 & 400 & 40 & 20 & 8.95338 \\
\hline$\alpha(\mathrm{m} 2 / \mathrm{s})$ & 1.47 & 93 & 1163 & 1317 & 57.45 & 30.7 \\
\hline
\end{tabular}

Table1. Thermo physical Properties of Nanoparticles.

\section{WORKING OF HEAT PIPE}

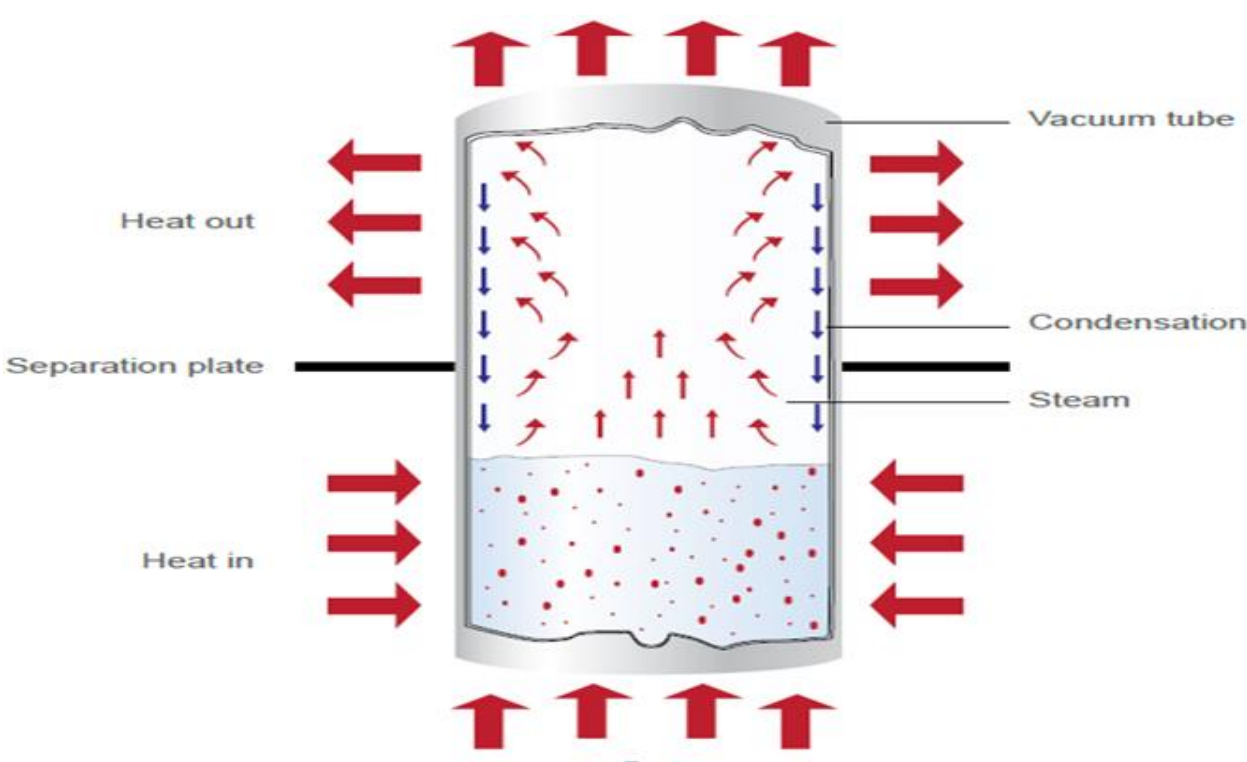

Figure 3: Working of Heat Pipe

The heat pipe is excellent in thermal conductivity; the other end of the heat pipe is the evaporation part and the other end of the condensation section. When the vaporizer is heated, the heat pump fluid evaporates quickly. This vapor releases its heat to the condenser with a small vapor pressure 
difference and condenses back into the liquid. The condensed liquid in the condensation part then flows back to the vaporizing section along the inner wall of the heat pipe and ends up in the endothermic evaporation in the evaporation part. The heat transfer of the heat pipe uses a working fluid that changes the steps in a continuous endothermic and exothermic cycle, whereby the heat pipe is excellent heat transfer.

\section{DEVELOPMENT OF TEST SETUP}

Heat exchangers are devices that made the energy exchange (waste heat) from the waste heat source to the colder source. Figure 4 is a schematic diagram of an experimental system. The system consists of three main parts: air heater (for boiler production), heat pipe heat exchanger and parameter measuring and control equipment. The installation has two recyclable liquids: hot substance (waste water) in the lower chamber of the heat exchanger and refrigerant in the upper heat exchanger (cold air).

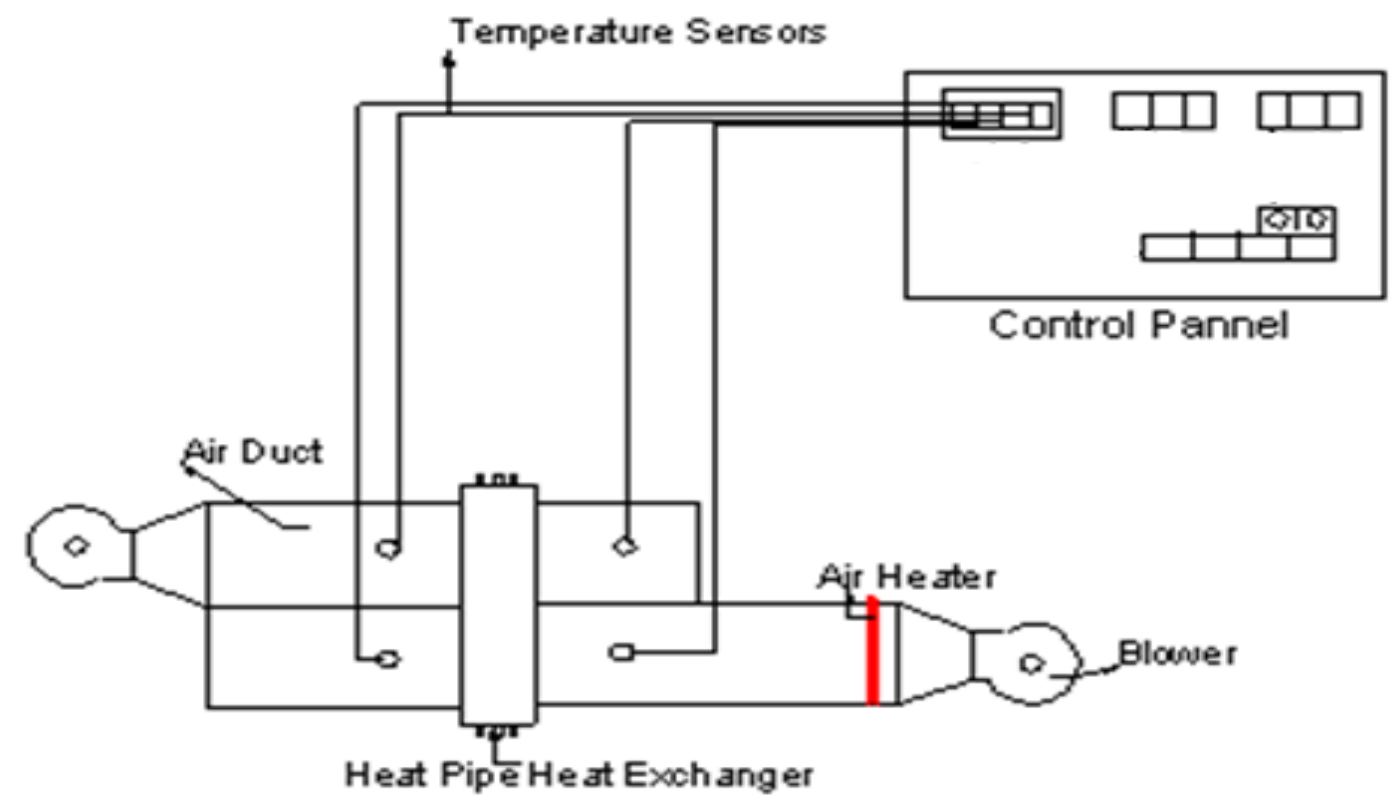

Figure 4: Schematic diagram of the experimental setup.

The heat pipe heat exchanger was equipped with eight heat pipes arranged vertically at an angle of $90^{\circ}$ (Figure 4). The working fluid used in heat pipe is $\mathrm{ZnO} / \mathrm{H} 2 \mathrm{O}$ nanofluid.

\section{TEST PARAMETERS}

Experimentation was carried on the TPCT HRHX. Working fluid is important parameter in the experimentation. $\mathrm{BN} / \mathrm{H} 2 \mathrm{O}$ nanofluid was used as a working fluid, other parameters and its description as follows. 


\begin{tabular}{|c|c|}
\hline Parameter & Description \\
\hline Heat load (W) & $250 \mathrm{~W}$ to $1500 \mathrm{~W}$ \\
\hline Source temperature & 25 to $650 \mathrm{C}$ \\
\hline Mass flow rate (m) & 0.0512 to $0.2749 \mathrm{~kg} / \mathrm{s}$ \\
\hline Discharge of Blower & 100 to $500 \mathrm{cfm}$ \\
\hline Velocity & 1.04 to $5.24 \mathrm{~m} / \mathrm{s}$ \\
\hline
\end{tabular}

Table 2.Test parameters

\section{CALCULATiONS}

\section{A. Heat Load Calculation}

While designing the heat pipe heat exchanger, we have to calculate the total heat load for proposed heat pipe heat exchanger. Assuming maximum inlet hot air temperature $60^{\circ} \mathrm{C}$ and corresponding ambient temperature $25^{\circ} \mathrm{C}$ with maximum mass flow rate of air as $0.2361 \mathrm{~kg} / \mathrm{sec}$. The heat load on heat exchanger can be calculated as follows,

Heat $\operatorname{Load}(\mathrm{Q})=\mathrm{m} \cdot \mathrm{C}_{\mathrm{p}} \cdot \Delta \mathrm{T}$

\section{Heat Load on Single Heat Pipe (QHeat Pipe)}

$$
=\frac{\text { Total Heat Load On Heat Exchanger }}{\text { No.of Heat Pipe }}
$$

\section{B. Heat Pipe Limit Calculation}

Heat pipes undergo various heat transfer limitations depending on the working fluid, the dimensions of the heat pipe, and the heat pipe operational temperature.

1. Viscous limitation

Viscous limit depends on the viscous pressure losses in vapor phase and the vapor pressure of the working fluid

$$
\begin{gathered}
Q_{v p}= \\
\frac{\pi \cdot r_{v}^{4} \cdot h_{f g} \cdot \rho_{v, e} \cdot P_{v, e}}{12 \cdot \mu_{v, e} \cdot l_{e f f}}
\end{gathered}
$$

\section{Sonic limitation}

The sonic limit is due to the fact that at low vapor densities, the corresponding mass flow rate in the heat pipe may result in very high vapor velocities, and the occurrence of choked flow in the vapor passage may be possible. 
O. M. Kshirsagar, Suchit Kawade, Vishal Ghodase, Mandar Kirange, and Shrikant Kamble

$$
Q s=0.474 A_{v} \cdot h_{f g} \cdot\left(\rho_{v} \cdot P_{v}\right)^{0,5}
$$

\section{Entrainment limitation}

The entrainment limit refers to the case of high shear forces developed as the vapor passes in the counter flow direction over the liquid saturated wick, where the liquid may be entrained by the vapor and returned to the condenser. This results in insufficient liquid flow of the wick structure.

$$
Q_{e}=A_{v} \cdot h_{f g} \cdot\left(\frac{\rho_{v} \cdot \delta_{1}}{2 \cdot r_{c, a v e}}\right)^{0.5}
$$

4. Boiling limitation

The boiling limit occurs when the applied evaporator heat flux is sufficient to cause nucleate boiling in the evaporator wick. This creates vapor bubbles that partially block the liquid return and can lead to evaporator wick dry out. The boiling limit is sometimes referred to as the heat flux limit.

$$
Q_{b}=\frac{4 \pi \cdot l_{e f f} \cdot \gamma_{e f} \cdot T_{v} \sigma_{v}}{h_{f g} \cdot \rho_{v} \cdot \ln \frac{r_{i}}{r_{e}}}\left(\frac{1}{r_{n}}-\frac{1}{r_{c, e}}\right)
$$

\section{CONCLUSION}

We studied the working principle of the heat pipe. And replace the working fluid by nanofluid Zno $/ \mathrm{H} 2 \mathrm{O}$.

- The performance of heat pipe heat exchanger charged with $\mathrm{ZnO} / \mathrm{H} 20$ nanofluid increases with increase in source temperature.

- The results obtained for TPCT heat exchanger charged $\mathrm{ZnO} / \mathrm{H} 20$ nanofluid are superior with that of TPCT charged with conventional fluid

- Enhancement in effectiveness of heat exchanger for current study is about 35\% compared with the available literature. 


\section{REFERENCES}

[1] Yodrak L., Sampan R., 'Waste Heat Recovery by Heat Pipe Air-Preheater to EnergyThrift from the Furnace in a Hot Forging Process', American Journal of Applied Sciences2010. 7 (5),pp 675681.

[2] Noie-Baghban, MajideianG., 'Waste heat recovery using heat pipe heat exchanger(HPHE) for surgery rooms in hospitals', Journal of Applied Thermal Engineering, 2000, pp 1271-1282,.

[3] Wilkes G., GrantD., 'Angry Trout Cafe Kitchen Exhaust Heat RecoveryFinal Report for CARD Grant B42832', Conservation Applied Research \& Development (CARD) Program, 2012.

[4] Niu J., Zhang L., Zuo H.,'Energy savings potential of chilled ceiling combined with desiccant cooling in hot and humid climates', Energy and Buildings, 34(2002),pp 487-495.

[5] MeyerA, Dobson R., 'A heat pipe heat recovery heat exchanger for a mini-drier', Journal of Energy in S. Africa ,February 2006, Vol. 17.

[6] Mohammad A., 'Improving the Energy Performance of HVAC Systems in Operating Theatres by Using Heat Recovery Devices', International Journal of Renewable Energy Research, 2014 Vol.4.

[7] Jadhav T., Lele M., 'A case study on energy savings in air conditioning system by recovery using heat pipe heat exchanger', International Journal of Research in Engineering and Technology,Jan2014 Volume: 03 Issue: 01.

[8] Mostafa A., El-Baky, Mousa M.,'Heat pipe heat exchanger for heat recovery in air conditioning' Milan, Italy, 14-17 May, 2006,Vol. 2, pp. 659-668.

[9] S. Nozu, T. Fujii, H. Honda, "A method for estimating tube length and pressure drop of air-cooled condensers", Vol. 92, No. 2934, 1986.

[10] C.P. ARORA,Refrigeration and air conditioning, 3rd edition 2000

[11] James M. Calm, "Emissions and environmental impacts from air-conditioning and refrigeration systems",Vol 25, pp- 293-305, 2002.

[12] R. Cabello,E. Torrella, J. Navarro-Esbri, "Experimental evaluation of a vapour compression plant performance using R134a, RR407C and R22 as working fluids”, Vol24, 2004,pp- 1905-1917. 